\title{
The impact of tertiary wastewater treatment on copper and zinc complexation
}

\author{
C. Constantino ${ }^{\mathrm{a}^{*}}$, M. Gardner ${ }^{\mathrm{a}}$, S.D.W. Comber ${ }^{\mathrm{b}}$, M.D. Scrimshaw ${ }^{\mathrm{c}}$ and B. \\ Ellor $^{\mathrm{d}}$
}

${ }^{a}$ Atkins Limited, Cilbrook Oasis Business Park, Eynsham, OX29 4AH, UK;

${ }^{b}$ Environmental Sciences, Plymouth University, Plymouth, PLA 8AA, UK; ${ }^{c}$ Institute for

the Environment, Brunel University, Uxbridge, UB8 3PH, UK; ${ }^{d} U K W I R, 50$ Broadway, London, SWIH ORG, UK

*Corresponding author. Tel: +44 (0)1865 734217. Email:

carlos.constantino@atkinsglobal.com

\begin{abstract}
Tightening quality standards for European waters have seen a move towards enhanced wastewater treatment technologies such as granulated organic carbon treatment and ozonation. Although these technologies are likely to be successful in degrading certain micro-organic contaminants these may also destroy compounds which would otherwise complex and render metals significantly less toxic. This study examined the impact of enhanced tertiary treatment on the capacity of organic compounds within sewage effluents to complex copper and zinc. The data show that granulated organic carbon treatment removes a dissolved organic carbon (DOC) fraction that is unimportant to complexation such that no detrimental impact on complexation or metal bioavailability is likely to occur from this treatment type. High concentrations of ozone (>1mg $\mathrm{O}_{3} / \mathrm{mg}$ DOC) are, however, likely to impact the complexation capacity for copper although this is unlikely to be important at the concentrations of copper typically found in effluent discharges or in rivers. Ozone treatment did not affect zinc complexation capacity. The complexation profiles of the sewage effluents show these to contain a category of non-humic ligand that appears unaffected by tertiary treatment and which displays a high affinity for zinc, suggesting these may substantially reduce the bioavailability of zinc in effluent discharges. The implication is that traditional metal bioavailability assessment approaches such as the Biotic Ligand Model may overestimate zinc bioavailability in sewage effluents and effluent impacted waters.
\end{abstract}

\section{Key words}

Effluent, copper, zinc, ozone, granulated organic carbon treatment, metal speciation 


\section{Introduction}

The United Kingdom (UK) Water Industry is currently assessing the effectiveness of advanced wastewater treatment technologies such as granular activated carbon (GAC) and ozonation for reducing the concentrations of priority organic chemicals (e.g. steroid hormones) in sewage effluents, with reported evidence that advanced treatment technologies may be effective [1 to 6]. It is also known that dissolved organic matter present in wastewater treatment works (WwTWs) effluents is capable of complexing metals to render them considerably less toxic to receiving waters [7-9]. Consequently, adsorptive or destructive tertiary treatment methods may also have some effect on the capacity of the dissolved organic matter present in sewage effluent to bind metal ions, and therefore on the bioavailability (and subsequent toxicity) of metals in WwTW discharges. The potential effect of advanced wastewater treatment on metal bioavailability is of particular significance since sewage effluents can represent a substantial source of metal inputs into the aquatic environment and it is important to ensure that efforts aimed at reducing risk from one category of priority chemical do not, inadvertently, increase the risk from another category of priority chemical (e.g. metals). Indeed, enhanced removal of metals is also an important objective of wastewater treatment $[10,11]$.

The actual effect of advanced treatment technologies on metal bioavailability in sewage effluent is, however, uncertain and not well explored. For example, although the complete destruction of organic ligands might release more bioavailable metal in the environment, the partial destruction of organic ligands might also give rise to a category of smaller ligand that might increase the effluent capacity to complex metals ions, thus reducing metal bioavailability.

Furthermore, when considering the management of anthropogenic chemicals entering the environment, it is important to assess the extent by which the metal complexing characteristics of sewage effluent derived organic matter differ from that of organic matter derived from natural sources. Indeed, powerful synthetic complexants have been detected in effluents that are known to influence metal bioavailability [12, 13]. The environmental regulator for England, the Environment Agency, has proposed specifying water quality standards for copper and zinc in terms of a permissible bioavailable concentration. Under this regulatory regime, computational models based on the Biotic Ligand Model [14-15], which take account of site-specific physico-chemical conditions such as $\mathrm{pH}$ and the concentrations of organic matter and calcium on metal bioavailability and allow an estimation of the metal fraction that is bioavailable. The models, however, assume that organic matter is derived from natural sources, consisting primarily of humic substances, whereas effluent derived organic matter is known to be comprised substantially of non-humics, including polycellular exudates, proteins, and other anthropogenic substances [16-18].

The aims of this research were therefore to assess the impacts of advanced tertiary treatment (ozonation, granulated activated carbon and UV exposure, in various combinations) on metal speciation as well as potential differences in complexation capacity and strength between natural and WwTW derived ligands. Ultimately, such data allow an evaluation of the differences in the complexation characteristics of effluent and naturally derived organic matter, and therefore the extent by which models calibrated for natural waters may be appropriate for waters which receive substantial effluent inputs. This research was carried out as part of a series of technical 
investigations that were undertaken between 2010 to 2013 by UK water companies as part of a research programme (the Chemicals Investigation Programme, or CIP) into the management and control of substances likely to be found in sewage.

\section{Methods and materials}

\section{Effluent selection}

Effluent samples were obtained from pilot plants at two WwTWs. The treated sewage was derived from primarily domestic sources. Descriptions of the effluents (anonymised) and treatment types that were examined as part of this study are provided in Table 1. Samples were taken before (final effluent) and after the tertiary treatment stages.

\section{Table 1 Description of effluents and advanced process treatments}

\section{Sample handling}

Effluent samples were collected in acid washed 10 litre high density polyethylene (HDPE) containers from the wastewater treatment works in August and December 2011, respectively. The samples were filtered through $0.45 \mu \mathrm{m}$ cellulose nitrate membrane filters (Whatman, UK) on-site and stored in acid washed 10 L HDPE containers and packed in ice until return to the laboratory where they were stored at $4^{\circ} \mathrm{C}$ in the dark.

\section{Complexation capacity titration}

Complexation characteristics were assessed using a Chelex column method [19, 20]. The Chelex column method involves passing a water sample through a column packed with (an ion exchange) Chelex resin within which labile metal species (i.e. free metal ions or ions in weak complexes that dissociate upon contact with the Chelex) are retained.

Complexation characteristics (binding capacity and affinity) were determined by adding metal to aliquots of $0.45 \mu \mathrm{m}$ filtered sample and assessing the relationship between the pre-column and post-column metal concentrations. Complexation capacity represents the post-column concentration at which an increase in the pre-column concentration does not result in an increase in the post-column concentration (i.e. the concentration at which the available complexing ligands become saturated). Binding affinity represents a measure of strength of the complexes formed and is determined from the rate at which the post-column (non-labile) concentration increases.

Complexation characteristics determined by the Chelex column method are operationally defined since these are dependent on the flow rate through the column and contact time with the resin. Since weakly bound metal species are also retained within the column the Chelex method provides a conservative measure of complexation which, for the purposes of assessing risk, is useful since, as already described, the complexation characteristics exclude the contribution from weakly bound metal complexes that might dissociate and therefore become bioavailable. 
Calcium-form Chelex columns were prepared in $50 \mathrm{~mm}$ (height) by $7 \mathrm{~mm}$ (internal diameter) borosilicate glass columns (Bio-Rad, USA) with Chelex-100 (200-400 mesh, Bio-Rad, USA) as the chelating resin. $1 \mathrm{~mL}$ of wet sodium-form Chelex slurry was inserted into each column, and plugged with glass wool. The Chelex resin was converted to calcium form by pumping at least $10 \mathrm{~mL}$ of $2 \mathrm{M}$ calcium chloride solution through each column at a flow rate of $20 \mathrm{ml} / \mathrm{minute}$. For samples the flow rate was 50 $( \pm 2) \mathrm{mL} /$ minute. Flow through the column was controlled using a $302 \mathrm{~S} / \mathrm{RL}$ Watson Marlow peristaltic pump.

As part of the sample preparation protocol, the $\mathrm{pH}$ of each sample was stabilised by the addition of reagent grade 3-(N-morpholino)propanesulphonic acid (MOPS) to a final concentration of $0.05 \mathrm{M}$ and adjusted to $\mathrm{pH} 7.0( \pm 0.05)$ using $1 \mathrm{M}$ hydrochloric acid $(\mathrm{HCl})$. At least 10 aliquots of $200 \mathrm{~mL}$ filtered sample were spiked with a metal standard, prepared as 50mg/L solutions in dilute Optima grade nitric acid (1\%) (Fisher, UK), using reagent grade commercially available metal nitrate salts (Fisher, UK). Samples were spiked with copper so that the aliquot concentrations increased in increments of $50 \mu \mathrm{g} / \mathrm{L}$ and with zinc so that the aliquot concentrations increased in increments of $10 \mu \mathrm{g} / \mathrm{L}$.

The spiked aliquots were equilibrated for one hour to standardise the kinetic conditions and passed through two separate Chelex columns. For each aliquot $50 \mathrm{~mL}$ was collected before being passed through the columns and $50 \mathrm{~mL}$ from after each column.

To assess differences in complexation characteristics of effluent and naturally derived organic matter, a $10 \mathrm{mg} / \mathrm{L}$ solution standard was prepared from Suwannee River Fulvic acid (SRFA) reference material obtained from the International Humic Substances Society (IHSS) which is considered to be broadly representative of organic matter with a natural origin. SRFA has been used by researchers worldwide and its properties have been characterised extensively. Complexation characteristics were determined for the SRFA samples as described above, except that the solution ionic strength was adjusted to $0.01 \mathrm{M}$ with potassium chloride $(\mathrm{KCl})$.

\section{Analytical techniques}

Copper and zinc were quantified by flame atomic absorption spectrometry using an AAnalyst 100 (Perkin Elmer, UK). Dissolved organic carbon (DOC) was quantified using a TOC- $\mathrm{V}_{\mathrm{CPN}}$ total organic carbon analyser (Shimadzu, UK). A number of studies [21-22] have demonstrated that Specific UltraViolet Absorbance (SUVA) characteristics may provide a relatively straight-forward method for assessing the content of aromatic substances (e.g. carboxylates) in organic matter that have traditionally been considered to represent the substance category that is most significant with regard to ion binding. Indeed, SUVA has been proposed as an alternative to DOC as a BLM input [22]. SUVA was determined for all samples at $350 \mathrm{~nm}$ in $1 \mathrm{~cm}$ quartz cell using a UV-VIS 200 spectrophotometer (Perkin Elmer, UK). Samples were adjusted to $\mathrm{pH} 7$ prior to measurement. SUVA coefficients $(\varepsilon)$ for the selected wavelengths were calculated as follows:

$$
\varepsilon 350=\mathrm{A} 350 /(\mathrm{d} \cdot[\mathrm{DOC}])
$$


In the equation A350 represents the measured absorbance at $350 \mathrm{~nm}$, d the path length through the quartz cell $(\mathrm{cm})$ and $[\mathrm{DOC}]$ the DOC concentration $(\mathrm{mg} / \mathrm{L})$.

\section{Data treatment and analysis}

Complexation characteristics were determined from the Chelex data by fitting a nonlinear receptor binding equation [20] to the Chelex titration data:

$$
Y=\frac{B_{\max } \cdot X}{K_{d}+X}
$$

In the equation $Y$ represents the post-column (non-labile) metal concentration (in molar units), normalised on the basis of the concentration of dissolved organic carbon (DOC) to allow comparison of samples with different amounts of organic matter, and $\mathrm{X}$ the pre-column metal concentration (also in molar units). $\mathrm{B}_{\max }$ represents the point at which the available complexing ligands become saturated (i.e. complexation capacity) and $\mathrm{K}_{\mathrm{d}}$ the dissociation constant, which is also the reciprocal of the complex formation constant $(\mathrm{K})$ that is commonly used to describe binding affinity. The values for $\mathrm{K}_{\mathrm{d}}$ and $\mathrm{B}_{\max }$ are operationally defined since these are dependent on the sample flow rate through the column as well the metal ion affinity for the Chelex resin.

For each titration series the data from the duplicate Chelex columns were pooled which allowed the effect of differences between individual columns as well as differences due to random variation in the measured values to be taken into account. The best fitting value $B_{\max }$ and $K_{d}$ were those which minimised the sum of squared residuals determined using a customised Excel spreadsheet titration analyser. Confidence interval values for $\mathrm{B}_{\max }$ and $\mathrm{K}_{\mathrm{d}}$ were determined using a Monte Carlo method [24] whereby the residuals were applied randomly (with replacement) to the measured values and new values for $\mathrm{B}_{\max }$ and $\mathrm{K}_{\mathrm{d}}$ calculated. The confidence interval limits for $\mathrm{B}_{\max }$ and $\mathrm{K}_{\mathrm{d}}$ were the $2.5 \%$ ile and $97.5 \%$ ile values from 1,000 simulations (i.e. the $95 \%$ confidence interval range).

\section{Results}

\section{Sample characteristics}

The SUVA characteristics for the effluent and SRFA samples are provided in Table 2. For WwTW 1, the SUVA for the final effluent and GAC treated effluents were similar (i.e. 0.0051 vs. 0.0053), suggesting the GAC (adsorptive) treatment has no substantial effect on aromaticity. The SUVA for the ozone treated sample was, however, substantially lower than for the final effluent and GAC treated samples, by more than a factor of two, indicating the ozonation reduced the aromatic content.

For WwTW 2, the SUVA for both ozone treated effluents was lower than in the final effluent which, as for WwTW 1, suggested ozone treatment to have a destructive impact on aromatic content. The reduction in SUVA was also greatest in the Ozone 2 treated effluent in which a substantially higher ozone dose was applied suggesting a relationship between the impact on aromatic content and the applied ozone concentration. 
The SUVA for the WwTW 2 final effluent sample (0.0094) exceeded that for WwTW 1 final effluent (0.0051, Table 2) and was potentially indicative of differences in the organic matter inputs to the treatment works. The SUVA for the SRFA sample (0.0162) was greater than for all the effluents, demonstrating SRFA to have the greatest aromatic content.

\section{Table 2 Physico-chemical characteristics of effluent and SRFA}

\section{The effect of advanced treatment on copper and zinc complexation}

\section{$\underline{W w T W 1}$}

The copper complexation characteristics for WwTW 1 and SRFA samples are provided in Figure 1. Both the GAC and ozone treatment did not have any significant influence on binding affinity and resulted in a small increase in the DOC normalised complexation capacity, potentially attributable to the reduction in the DOC concentration in the ozone and GAC treated effluents, indicating the elimination of a DOC fraction that is relatively unimportant to complexation. This suggests that the tertiary treatments applied at WwTW 1 are unlikely to impact copper bioavailability entering the aquatic environment via WwTW effluent.

The comparison of final effluent and SRFA complexation characteristics indicated no difference in the binding affinity, but that the SRFA sample contained a greater concentration of copper complexing ligands (per mg of DOC). The implication is that effluent derived organic matter may, to some extent, be less protective than organic matter derived from a natural source. It is, nonetheless, important to recognise that, as a consequence of the substantial complexation capacity potential in both the effluent and SRFA samples, the significance of this difference at environmentally relevant copper concentrations may well be marginal.

\section{Figure 1 near here}

Zinc complexation characteristics for the WwTW 1 samples are provided in Figure 2. The data indicate that both the ozone and GAC treatments did not have any significant impact on binding affinity although both treatments appeared to produce a similar increase in complexation capacity. As for copper, this suggests that the relative increase in (DOC normalised) complexation capacity may be attributable to the removal/elimination of some DOC fraction unimportant for binding zinc. These results suggest that the tertiary treatments operated at WwTW 1 are unlikely to impact the bioavailability of zinc in effluent discharges.

Complexation characteristics could not, however, be determined for the SRFA sample since the post-column concentrations of zinc were below the analytical limit of detection $(<5 \mu \mathrm{g} / \mathrm{L})$. This result was interesting in itself since the occurrence of postcolumn zinc in the effluent samples suggests that the effluents contained a category of ligand with an affinity for zinc that is substantially greater than complexing ligands derived from natural sources (i.e. sufficient to mobilise zinc through the Chelex column). The implication is that compounds present in sewage effluents might offer a much higher degree of protection from the effects of exposure to zinc in comparison with the level protection offered by organic matter derived from natural sources. An 
additional and important implication is that the biotic ligand models might substantially overestimate the bioavailability of zinc in effluent discharges and in waters which receive effluent inputs.

\section{Figure 2 near here}

\section{$\underline{W w T W 2}$}

As for the WwTW 1, copper complexation characteristics for WwTW 2 and SRFA samples indicated that there was no significant difference between the binding affinities, although a large difference in complexation capacity between the ozone 2 treated effluent and the other effluents was evident (Figure 3). The Ozone 2 treated effluent sample was unique in that it had been subject to a substantially higher ozone dose (16 $\mathrm{mg} / \mathrm{L})$ in comparison with the dose applied during the Ozone 3 treatment and at the WwTW 1 pilot plant (both $2 \mathrm{mg} / \mathrm{L}$ ). This suggests that high concentrations of ozone have the capacity to reduce copper complexation capacity in a manner that could potentially increase copper bioavailability. It is, however, important to recognise that, as a consequence of the substantial complexation capacity potential in the effluent samples, and that the sample binding affinities remained similar, a significant increase in risk at environmentally relevant concentrations of copper would appear unlikely.

The result of the comparison of final effluent and SRFA complexation characteristics was similar to that for WwTW 1 in that the SRFA sample demonstrated a substantially greater copper complexation capacity per unit weight of DOC compared with the effluent samples, with the possible consequences as described above.

\section{Figure 3 near here}

Overall the binding capacity for zinc was significantly less than that for copper (2.5 to 5 compared with 10 to $25 \mu \mathrm{g} / \mathrm{mg}$ DOC respectively). No significant effect on zinc binding affinity or complexation capacity as a consequence of the ozone treatments could be identified for WwTW 2 and suggested that the treatments did not have any significant impact on the zinc complexing ligands (Figure 4). A substantial degree of uncertainty was, however, associated with the binding affinity value for the Ozone 2 sample, which is reflected in the large confidence interval range values for this sample (not rendered in Figure 4).

\section{Figure 4 near here}

\section{The relationship between copper and zinc complexation and SUVA}

The relationship between SUVA and copper and zinc complexation capacity is illustrated in Figures 5 and 6, respectively. The results for copper (Figure 5) show no clear relationship between complexation capacity and SUVA for the effluent samples, the implication being that complexation capacity may be attributable to a category of non-humic ligand. The SUVA and complexation capacity values for SRFA also exceeded those of the effluent samples. For WwTW 1, whereas the GAC treatment did not demonstrate any significant impact on SUVA, the small increase in DOC normalised complexation capacity (relative to the final effluent sample) may have been indicative of the elimination of a low SUVA DOC fraction that was relatively unimportant to complexation. The ozone treatments reduced SUVA in all instances, 
with the largest reduction for the WwTW 2 Ozone 2 treated effluent that had the highest ozone dose.

The results for zinc (Figure 6) similarly show do not show any clear relationship between complexation capacity and SUVA for the effluent samples. In contrast with the results for copper, however, the results for zinc show that the complexation capacities of the effluent samples substantially exceed that of the SRFA sample. The results confirm SUVA to be a poor predictor of zinc complexation and consequently that non-humic substances are likely to be of particular significance to zinc binding in sewage effluent and effluent impacted waters. The results for both copper and zinc, however, demonstrate that non-humic substances present in sewage effluent represent an additional ligand category that contributes to complexation capacity, and thereby the potential to influence metal bioavailability.

\section{Figure 5 near here}

\section{Figure 6 near here}

\section{Discussion \\ The effect of advanced wastewater treatment on metal complexation}

The treatment technologies evaluated in this study are not commonly used to treat sewage effluent, however, in the context of drinking water treatment, GAC is often applied as a treatment following other more destructive treatment options such as ozonation in order to remove treatment by-products such as aldehydes, carboxylic acids and other low molecular weight biodegradable organic compounds such as pesticides [25]. Indeed, a study by Treguer et al. [26] also found that low molecular weight molecules were preferentially removed by GAC treatment; a characteristic attributable to the fact that smaller molecules are better able to diffuse further into the pores of adsorbent material in comparison with larger molecules. The implication of the findings from the other studies $[25,26]$ is that GAC is likely to be relatively ineffective at removing the large (humic) molecules traditionally associated with metal complexation; a result supported by both the complexation capacity and SUVA results from the present study. In combination, these suggest that GAC treatment is unlikely to significantly impact copper or zinc bioavailability in effluent discharges.

Destructive treatments such as ozonation are typically applied to break large molecules to increase their biodegradability which facilitates their removal from the water. In the present study, the reduction in SUVA in response to ozone treatment (0.0094 vs. 0.0015) indicated that the ozone treatment did result in the destruction of the larger humic molecules. Furthermore, the relatively sharp reduction in SUVA for the Ozone 2 treated sample at WwTW 2 in comparison with the lowered powered ozone treatment at WwTW 1 and WwTW 2 Ozone 3 treated effluent also suggested that the extent of the impact corresponded with the ozone dose. A study by Siddiqui et al. [27], however, found that the reduction in humic context as a consequence of ozone treatment reached an optimal level at $1 \mathrm{mg} \mathrm{O} / \mathrm{mg}$ DOC, which was lower than the rate applied in the Ozone 2 treated effluent $(1.4 \mathrm{mg} \mathrm{O} / \mathrm{mg}$ DOC). The implication is therefore that impact on SUVA for the Ozone 2 treated sample is likely to represent an extreme example and also one in which further reductions in SUVA, or indeed complexation capacity, would be unlikely, even at higher ozone doses. The significance of the impact on copper complexation capacity is, however, uncertain; for example, although reduced, the 
copper complexation capacity in the post-Ozone 2 treated effluent was, nonetheless, sufficient to complex the concentration of dissolved copper typically present in sewage effluent $(<8 \mu \mathrm{g} / \mathrm{L})$. Indeed, at low, environmentally relevant copper concentrations the complexing ligands with the highest affinity for copper are likely to be of greatest relevance in influencing copper bioavailability. Since the Ozone 2 treated effluent did not demonstrate any significant influence on binding affinity a significant impact on the ligands with the highest binding affinity appears unlikely.

In contrast with the result for copper, ozone treatment did not have any impact on zinc complexation. SUVA was also generally a poor predictor of zinc complexation capacity, which was in agreement with findings from other recent studies [28], suggesting that non-humic substances may be of particular significance to binding zinc ions in sewage effluent and effluent impacted waters.

Indeed, this is supported by findings from other studies of the existence of a category of effluent derived ligand with a high affinity for zinc [29] which contributes further support for recommendations that the contribution to complexation capacity from anthropogenic ligands be included as an additional ligand category in biotic ligand modelling [30, 31].

\section{Implications for bioavailability based standards}

In the UK the environmental regulator, the Environment Agency, has proposed specifying new standards for copper and zinc in terms of a permissible bioavailable concentration, where bespoke BLM-type models are used to 'convert' the permissible bioavailable concentration into a dissolved metal concentration which serves as the compliance statistic. BLMs 'convert' the permissible bioavailable concentration into a dissolved metal concentration by simulating the influence of site-specific chemical characteristics ( $\mathrm{pH}$ and the concentrations of DOC and calcium) on metal bioavailability [32]. In its simulation of chemical interactions, however, the models assume that DOC is comprised entirely of humic substances which have been demonstrated to be primarily responsible for complexing copper ions in natural water systems. The strong UV-absorbance characteristics of humic substances have also formed the basis for recommendations that SUVA may be more useful than the DOC concentration as an indicator of complexation capacity [22] since the DOC concentration alone also reflects carbon species that are relatively unimportant to metal complexation. Whereas this approach may be appropriate for natural water systems, studies [28-31] have, however, identified that effluents and anthropogenically impacted waters may contain a category of non-humic ligand (including human-derived and synthetic) that binds very strongly with a variety metal ions (including copper, zinc, and nickel). These findings have also lead to recommendations that non-humic ligands be included as an additional ligand category in biotic ligand modelling. The results from this study, for zinc in particular, further support this hypothesis. Indeed, the results for zinc suggest the presence of a category of high affinity ligand in sewage effluents that is sufficiently robust to withstand ozone treatment. Failure to take into account the effect of these ligands might result in the overestimation of metal bioavailability, that might ultimately result in requirement to reduce the concentrations of metal in effluent discharges but which does not deliver any environmental benefit. This is of particular significance in receiving waters with low effluent dilution capacity. More research is, however, required in order to identify the ligands that may be responsible for the enhanced complexation capacity and the extent to which they may persist in surface waters. 


\section{Conclusions}

The following are the key findings from this study:

- GAC treatment removes a DOC fraction that is unimportant to the complexation of copper and zinc such that no detrimental impact on complexation or metal bioavailability is likely to occur from this treatment type.

- High concentrations of ozone (>1mg $\mathrm{O}_{3} / \mathrm{mg}$ DOC) are likely to impact copper complexation capacity. Sewage effluents, however, offer substantial copper complexation capacity such that the complexation capacity reduction is unlikely to influence copper bioavailability at the concentrations of copper typically found in effluent discharges. Ozonation is therefore unlikely to practically increase the bioavailability of copper in effluent discharges.

- Even high concentrations of ozone (>1mg $\mathrm{O}_{3} / \mathrm{mg}$ DOC) are unlikely to impact zinc complexation capacity or the bioavailability of zinc in effluent discharges.

- Sewage effluents contain a category of non-humic ligand. These non-humic ligands display complexation characteristics that differ substantially from ligands present in samples derived from natural sources. This ligand category displays a high affinity for zinc which suggests these may substantially reduce the bioavailability of zinc in effluent discharges to the extent that the traditional BLM approach might substantially overestimate zinc risk in sewage effluents and effluent impacted waters.

- The complexation capacity of DOC derived from a natural source demonstrates an overall greater capacity to complex copper than effluent derived organic matter although these differences are unlikely to be significant at environmentally relevant concentrations at which there is a substantial excess of complexation capacity.

\section{Acknowledgement}

The authors wish to thank the co-ordinator of the CIP programme - UK Water Industry Research Ltd (UKWIR) for authorising the use of the information reported here, and the UK Water Utility companies Anglian, Dwr Cymru, Northumbrian, Scottish, Severn Trent, Southern, South West, Thames, United Utilities, Wessex and Yorkshire Water for their considerable efforts in generating it. The authors also wish to thank Anna de Polo for assisting with preparation for the laboratory work and the three anonymous reviewers for their helpful comments. 


\section{References}

[1] Luo Y, Guo W, Ngo HH, Nghiem LD, Hai FI, Zhang J, Liang S, Wang XC. A review on the occurrence of micropollutants in the aquatic environment and their fate and removal during wastewater treatment, Sci. Total Environ. 2014. 473:619-641.

[2] Gardner M, Jones V, Comber S, Scrimshaw MD, Coello-Garcia T, Cartmell E, Lester J, Ellor B. Performance of UK wastewater treatment works with respect to trace contaminants, Sci. Total Environ. 2012. 456: 359-369.

[3] Zupanc M, Kosjek T, Petkovšek M, Dular M, Kompare B, Širok B, Blažeka Z, Heath E. Removal of pharmaceuticals from wastewater by biological processes, hydrodynamic cavitation and UV treatment. Ultrason. Sonochem. 2013. 20:1104-1112.

[4] Oller I, Malato S, Sánchez-Pérez JA. Combination of Advanced Oxidation Processes and biological treatments for wastewater decontamination-A review. Sci. Total Environ. 2011. 409:4141-4166.

[5] Mahamuni NN, Adewuyi YG. Advanced oxidation processes (AOPs) involving ultrasound for waste water treatment: A review with emphasis on cost estimation. Ultrason. Sonochem. 2010. 17:990-1003.

[6] Yu H, Nie E, Xu J, Yan S, Cooper WJ, Song W. Degradation of Diclofenac by Advanced Oxidation and Reduction Processes: Kinetic Studies, Degradation Pathways and Toxicity Assessments. Water Res. 2013. 47: 1909-1918.

[7] van Veen EM, Burton N, Gardner M, Comber S. Speciation of Copper in Sewage Effluents and its Toxicity to Daphnia Magna. Environ. Toxicol. Chem. 2002. 21:275280.

[8] Pernet-coudrier B, Clouzot L, Varrault G, Tusseau-vuillemin M, Verger A, Mouchel J. Dissolved organic matter from treated effluent of a major wastewater treatment plant: Characterization and influence on copper toxicity. Chemosphere. 2008. 73:593-599.

[9] Sarathy V, Allen HE. Copper complexation by dissolved organic matter from surface water and wastewater effluent. Ecotox. Environ. Safe. 2005. 61:337-344.

[10] Inna D, Lester JN, Scrimshaw M, Cartmell E. Speciation and fate of copper in sewage treatment works with and without tertiary treatment: the effect of return flows. Environ. Technol. 2014. 35:1-9.

[11] Crane RS, Barton P, Cartmell E, Coulon F, Hillis P, Judd SJ, Santos A, Stephenson T, Lester JN. Fate and behaviour of copper and zinc in secondary biological wastewater treatment processes: I Evaluation of biomass adsorption capacity. Environ. Technol. 2010. 31:705-723.

[12] Peters A, Merrington G, Leverett D, Ellor B, Lofts S, Gravell A. The effect of advanced treatment of sewage effluents on metal speciation and (bio)availability. Bull. Environ. Contam. Toxicol. 2014. 92:248-252. 
[13] Comber S, Gardner M, Jones V, Ellor B. Source apportionment of trace contaminants in urban sewer catchments. Environ. Technol. 2014. 36:573-587.

[14] Di Toro DM, Allen HE, Bergman HL, Meyer JS, Paquin PR, Santore RC. Biotic ligand model of the acute toxicity of metals. 1. Technical basis. Environ. Toxicol. Chem. 2001. 20:2383-2396.

[15] Santore RC, Toro DMD, Paquin PR, Allen HE, Meyer JS. Biotic ligand model of the acute toxicity of metals. 2. Application to acute copper toxicity in freshwater fish and Daphnia. Environ. Toxicol. Chem. 2001. 20: 2397-2402.

[16] Vakondios N, Koukouraki E, Diamadopoulos E. Effluent organic matter (EfOM) characterization by simultaneous measurement of proteins and humic matter. Water Res. 2014. 63:62-70.

[17] Ma H, Allen HE, Yin Y. Characterization of isolated fractions of dissolved organic matter from natural waters and a wastewater effluent. Water Res. 2001. 35:985-996.

[18] Knepper TP. Synthetic chelating agents and compounds exhibiting complexing properties in the aquatic environment. Trac-Trend. Anal. Chem.2003. 22:708-724.

[19] Gardner M, van Veen EM. Comparability of copper complexation capacity determination by absorption by chelating resin column and cathodic stripping voltammetry. Anal. Chim. Acta. 2004. 501:113-117.

[20] Bowles KC, Apte SC, Batley GE, Hales LT, Rogers NJ. A rapid Chelex column method for the determination of metal speciation in natural waters. Anal. Chim. Acta. 2006. 558: 237-245.

[21] Richards JGPJ, Burnison BK, Playle RC. Effects of natural organic matter source on reducing metal toxicity to rainbow trout (Oncorhynchus mykiss) and on metal binding to their gills. Environ. Toxicol. Chem. 2001. 20:1159-1166.

[22] De Schamphelaere KAC, Vasconcelos FM, Tack FMG, Allen HE, Janssen C. Effect of dissolved organic matter source on acute copper toxicity to Daphnia magna. Environ. Toxicol. Chem. 2004. 23:1248-1255.

[23] Motulsky H, Christopoulos A. Fitting Models to Biological Data Using Linear and Nonlinear Regression. Oxford University Press, New York, USA. 2004. Chapter 36, Analyzing saturation radioligand binding data; p. 199-210.

[24] Motulsky H, Christopoulos A. Fitting Models to Biological Data Using Linear and Nonlinear Regression. Oxford University Press, New York, USA. 2004. Chapter 17, Generating confidence intervals by Monte Carlo simulations; p. 104-108.

[25] Sarathy SR, Stefan MI, Royce A, Mohseni M. Pilot-scale UV/H202 advanced oxidation process for surface water treatment and downstream biological treatment: effects on natural organic matter characteristics and DBP formation potential. Environ. Technol. 2011. 32:1709-1718. 
[26] Treguer R, Tatin R, Couvert A, Wolbert D. Ozonation effect on natural organic matter adsorption and biodegradation - Application to a membrane bioreactor containing activated carbon for drinking water production. Water Res. 2010. 44: 781788 .

[27] Siddiqui MS, Amy GI, Murphy BD. Ozone enhanced removal of natural organic matter from drinking water sources. Water Res. 1997. 31: 3098-3106.

[28] Louis Y, Pernet-Coudrier B, Varrault G. Implications of effluent organic matter and its hydrophilic fraction on zinc(II) complexation in rivers under strong urban pressure: aromaticity as an inaccurate indicator of DOM-metal binding. Sci. Total Environ. 2014. 490:830-837.

[29] Cheng T. Comparison of zinc complexation properties of dissolved organic matter from surface waters and wastewater treatment plant effluents. J Environ. Sci-China. 2005. 17:535-539.

[30] Baken S, Degryse F, Verheyen L, Merckx R, Smolders E. Metal complexation properties of freshwater dissolved organic matter are explained by its aromaticity and by anthropogenic ligands. Environ. Sci. Technol. 2011. 45:2584-2590.

[31] Constantino C, Scrimshaw M, Comber S, Churchley J. An evaluation of biotic ligand models predicting acute copper toxicity to Daphnia magna in wastewater effluent. Environ. Toxicol. Chem. 2011. 30: 852-860.

[32] Peters A, Merrington G, Brown B. Using biotic ligand models to help implement environmental quality standards for metals under the Water Framework Directive, Environment Agency, Bristol, UK. 2009. 
Table 1 Description of effluents and advanced process treatments

\begin{tabular}{|c|c|c|}
\hline Site & Treatment type & Treatment description \\
\hline \multirow{3}{*}{ WwTW 1} & Final effluent & $\begin{array}{l}\text { Activated sludge process treated which receives inputs } \\
\text { from primarily domestic sources. }\end{array}$ \\
\hline & GAC & $\begin{array}{l}\text { Final effluent sample subjected to GAC treatment } \\
\text { (with coal as the adsorbant) with a } 10 \text { minute contact } \\
\text { time. }\end{array}$ \\
\hline & Ozone 1 & $\begin{array}{l}\text { Final effluent sample subjected to advanced oxidation } \\
\text { process (AOP) treatment which utilised ozone } \\
\text { treatment to achieve a final ozone concentration of } 2 \\
\mathrm{mg} / \mathrm{L} \text { in combination with low level UV disinfection } \\
(254 \mathrm{~nm}) .\end{array}$ \\
\hline \multirow{3}{*}{ WwTW 2} & Final effluent & $\begin{array}{l}\text { Biofilter treated effluent which receives inputs from } \\
\text { domestic sources and from a local brewery. WwTWs } \\
\text { also operates biologically aerated flooded filters } \\
\text { (BAFFs) which are situated after the biofilters and } \\
\text { represent the final treatment stage prior to discharge } \\
\text { into the environment. In this study, however, effluent } \\
\text { derived from the biofilter treatment stage was used in } \\
\text { the comparison of metal complexation characteristics. }\end{array}$ \\
\hline & Ozone 2 & $\begin{array}{l}\text { Final effluent sample subjected to AOP treatment } \\
\text { which utilised ozone }(16 \mathrm{mg} / \mathrm{L}) \text { and hydrogen peroxide } \\
(15 \mathrm{mg} / \mathrm{L}) \text { in combination with low level UV treatment } \\
(254 \mathrm{~nm}) \text {. }\end{array}$ \\
\hline & Ozone 3 & $\begin{array}{l}\text { Final effluent sample subjected to a novel low-energy } \\
\text { oxidation treatment which generates ozone and UV in- } \\
\text { situ and utilises micro-bubble technology. The sample } \\
\text { assessed had been produced from batch mode } \\
\text { operation where } 170 \mathrm{~L} \text { of effluent had been subject to } \\
\text { ozone treatment over a } 4 \text { hour period to achieve an } \\
\text { ozone concentration of } 2 \mathrm{mg} / \mathrm{L} \text {. }\end{array}$ \\
\hline
\end{tabular}


Table 2 Physico-chemical characteristics of effluent and SRFA

\begin{tabular}{|c|c|c|c|}
\hline \multirow{2}{*}{ Source } & Sample type & DOC $(\mathbf{m g} / \mathbf{L})$ & $\mathbf{8 3 5 0 n m}$ \\
\hline \multirow{3}{*}{ WwTW 1 } & Final effluent & 5.82 & 0.0051 \\
\cline { 2 - 4 } & GAC & 4.56 & 0.0053 \\
\cline { 2 - 4 } & Ozone 1 & 5.15 & 0.0023 \\
\hline \multirow{3}{*}{ WwTW 2 } & Final effluent & 5.90 & 0.0094 \\
\cline { 2 - 4 } & Ozone 2 & 11.64 & 0.0015 \\
\cline { 2 - 4 } & Ozone 3 & 5.99 & 0.0076 \\
\hline SRFA & Fulvic acid & 4.78 & 0.0162 \\
\hline
\end{tabular}

Figure 1 The effect of advanced treatment on the copper complexation characteristics of effluent from WwTW 1 (FE = final effluent, Ozone = ozonation, GAC = granular activated carbon, SRFA $=$ Suwannee river fulvic acid).

Figure 2 The effect of advanced treatment on the zinc complexation characteristics of effluent from WwTW 1 (FE = final effluent, Ozone = ozonation, GAC = granular activated carbon).

Figure 3 The effect of advanced treatment on the copper complexation characteristics of effluent from WwTW 2 (FE = final effluent, Ozone = ozonation, GAC = granular activated carbon, $\mathrm{SRFA}=$ Suwannee river fulvic acid).

Figure 4 The effect of advanced treatment on the zinc complexation characteristics of effluent from WwTW 2 (FE = final effluent, Ozone = ozonation, GAC = granular activated carbon, $\mathrm{SRFA}=$ Suwannee river fulvic acid).

Figure 5 The relationship between copper complexation capacity and SUVA. The error bars represent the complexation capacity $95 \%$ confidence interval range. The solid line represents the linear relationship between complexation capacity and SUVA for the effluent samples (excludes SRFA).

Figure 6 The relationship between zinc complexation capacity and SUVA. The error bars represent the complexation capacity $95 \%$ confidence interval range. The solid line represents the linear relationship between complexation capacity and SUVA for the effluent samples (excludes SRFA). 


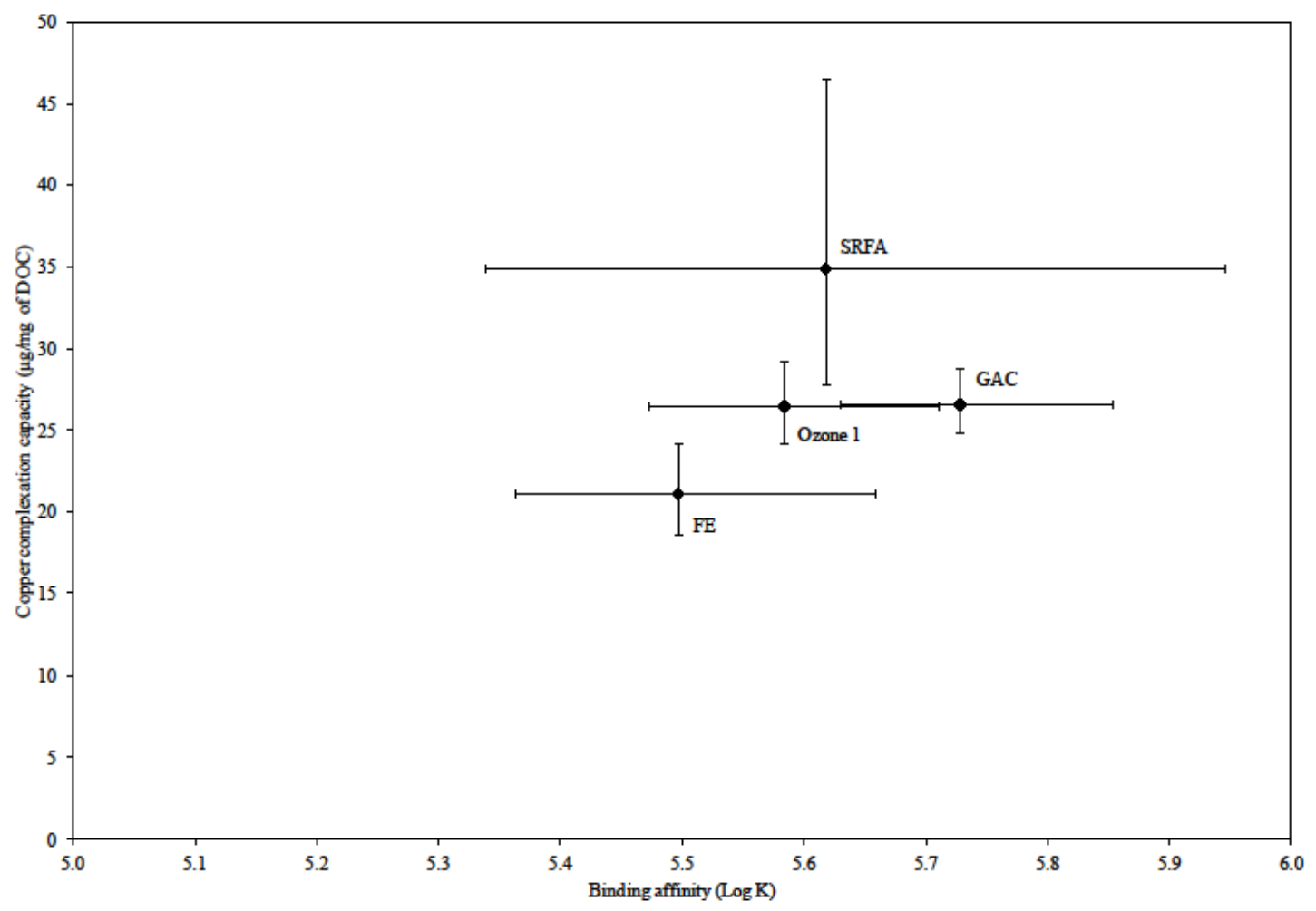

Figure 1 The effect of advanced treatment on the copper complexation characteristics of effluent from WwTW 1 (FE = final effluent, Ozone = ozonation, GAC = granular activated carbon, SRFA = Suwannee river fulvic acid). 


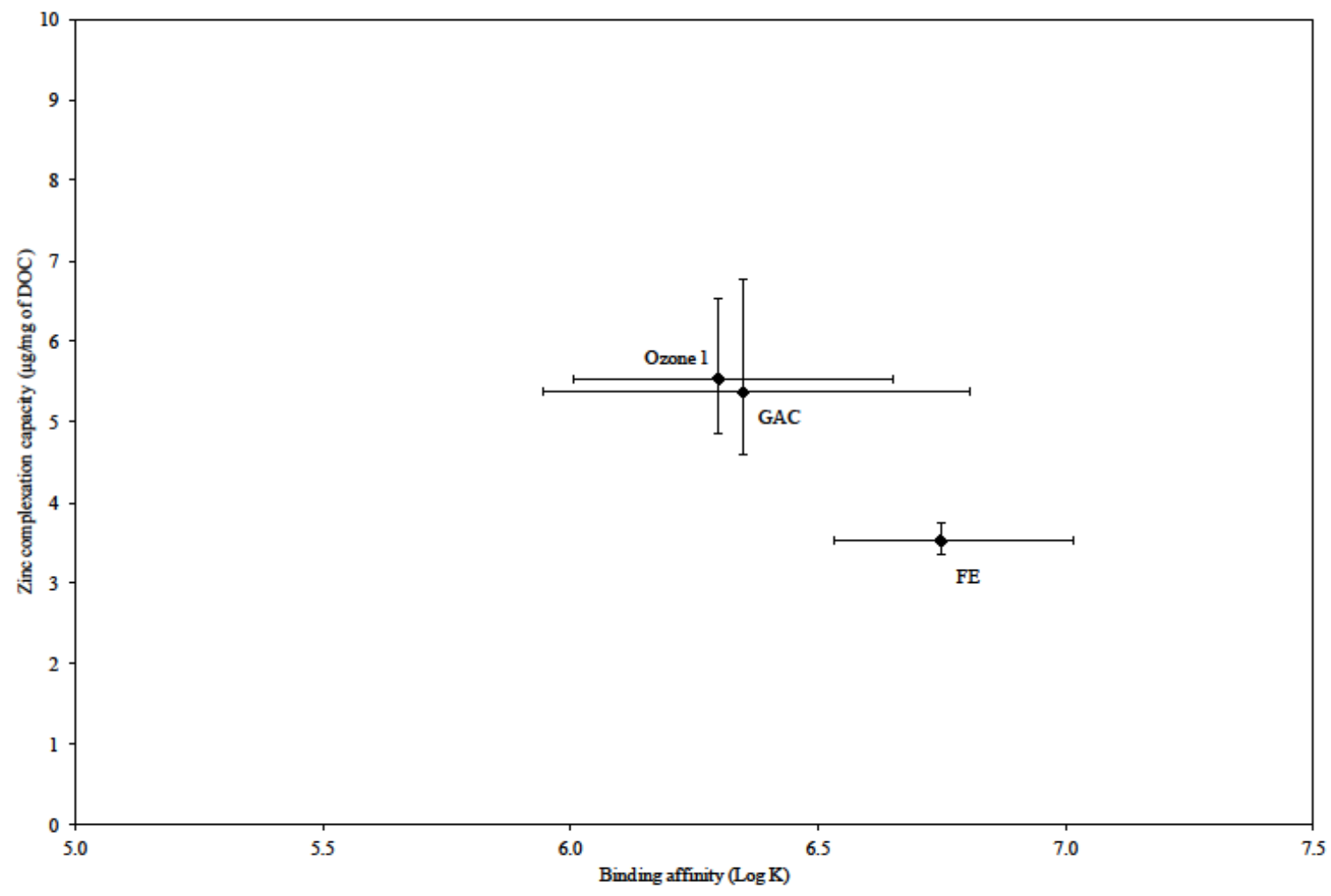

Figure 2 The effect of advanced treatment on the zinc complexation characteristics of effluent from WwTW 1 (FE = final effluent, Ozone = ozonation, GAC = granular activated carbon). 


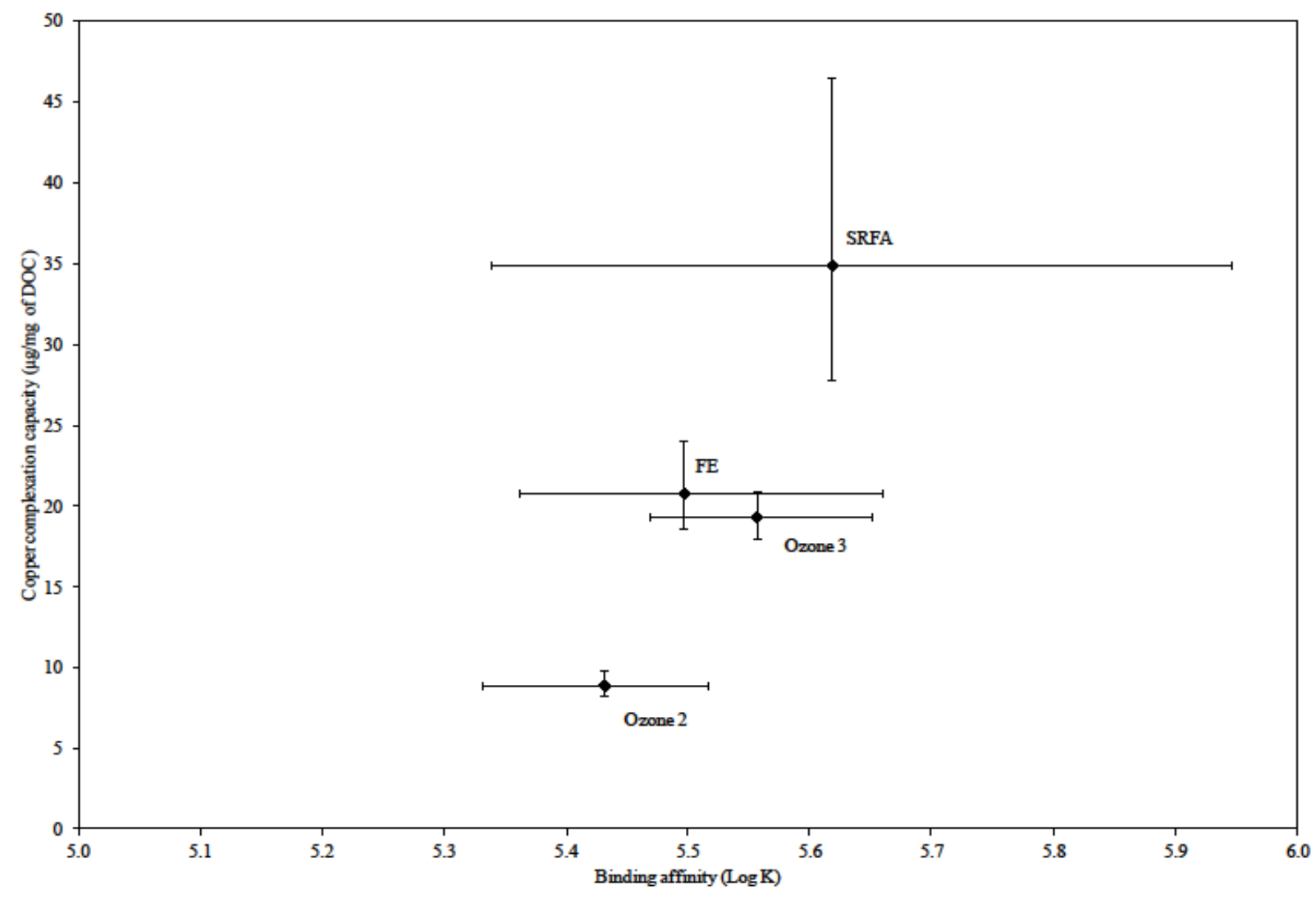

Figure 3 The effect of advanced treatment on the copper complexation characteristics of effluent from WwTW 2 (FE = final effluent, Ozone = ozonation, GAC = granular activated carbon, $\mathrm{SRFA}=$ Suwannee river fulvic acid). 




Figure 4 The effect of advanced treatment on the zinc complexation characteristics of effluent from WwTW 2 (FE = final effluent, Ozone = ozonation, GAC = granular activated carbon, $\mathrm{SRFA}=$ Suwannee river fulvic acid). 


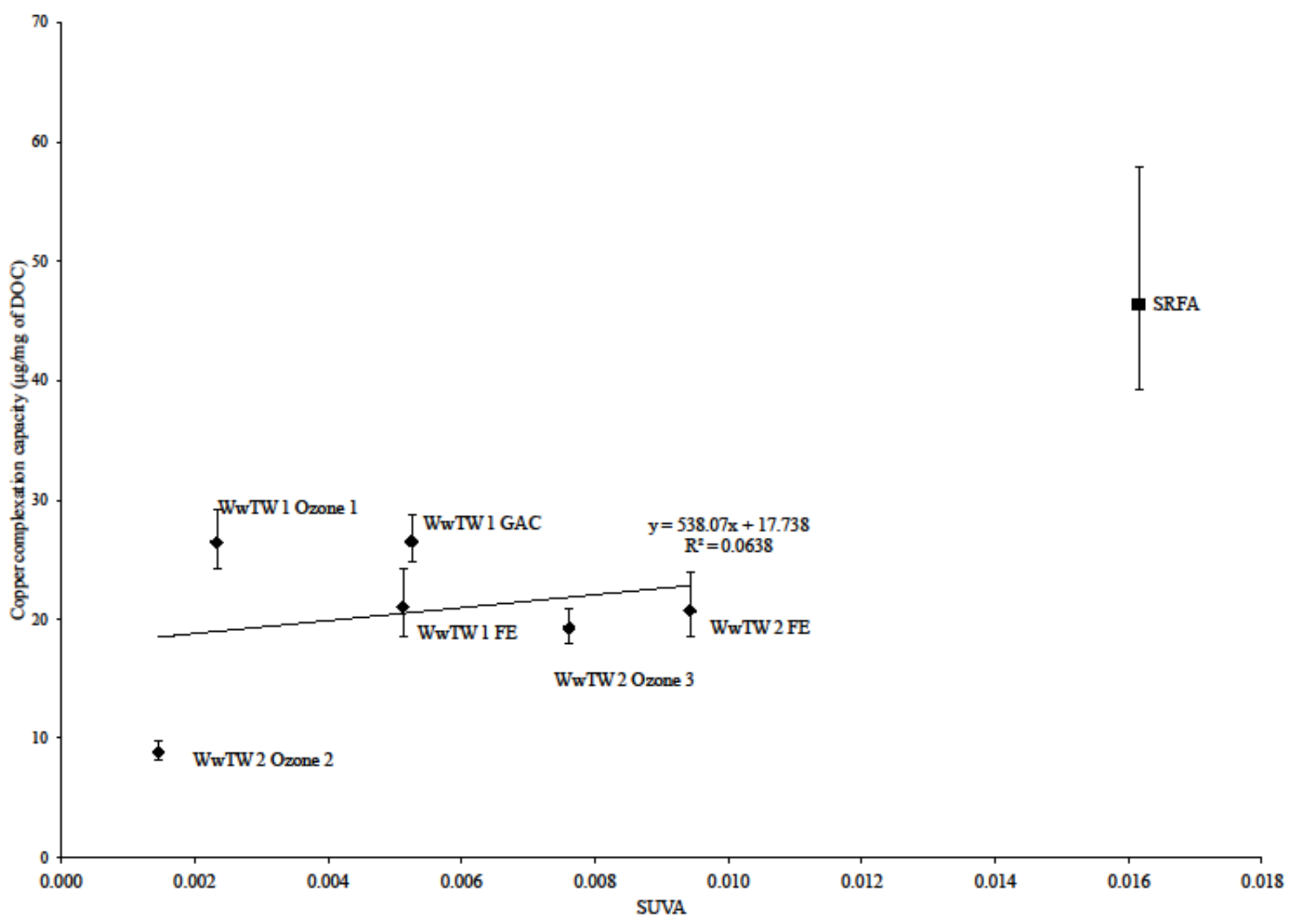

Figure 5 The relationship between copper complexation capacity and SUVA. The error bars represent the complexation capacity $95 \%$ confidence interval range. The solid line represents the linear relationship between complexation capacity and SUVA for the effluent samples (excludes SRFA). 


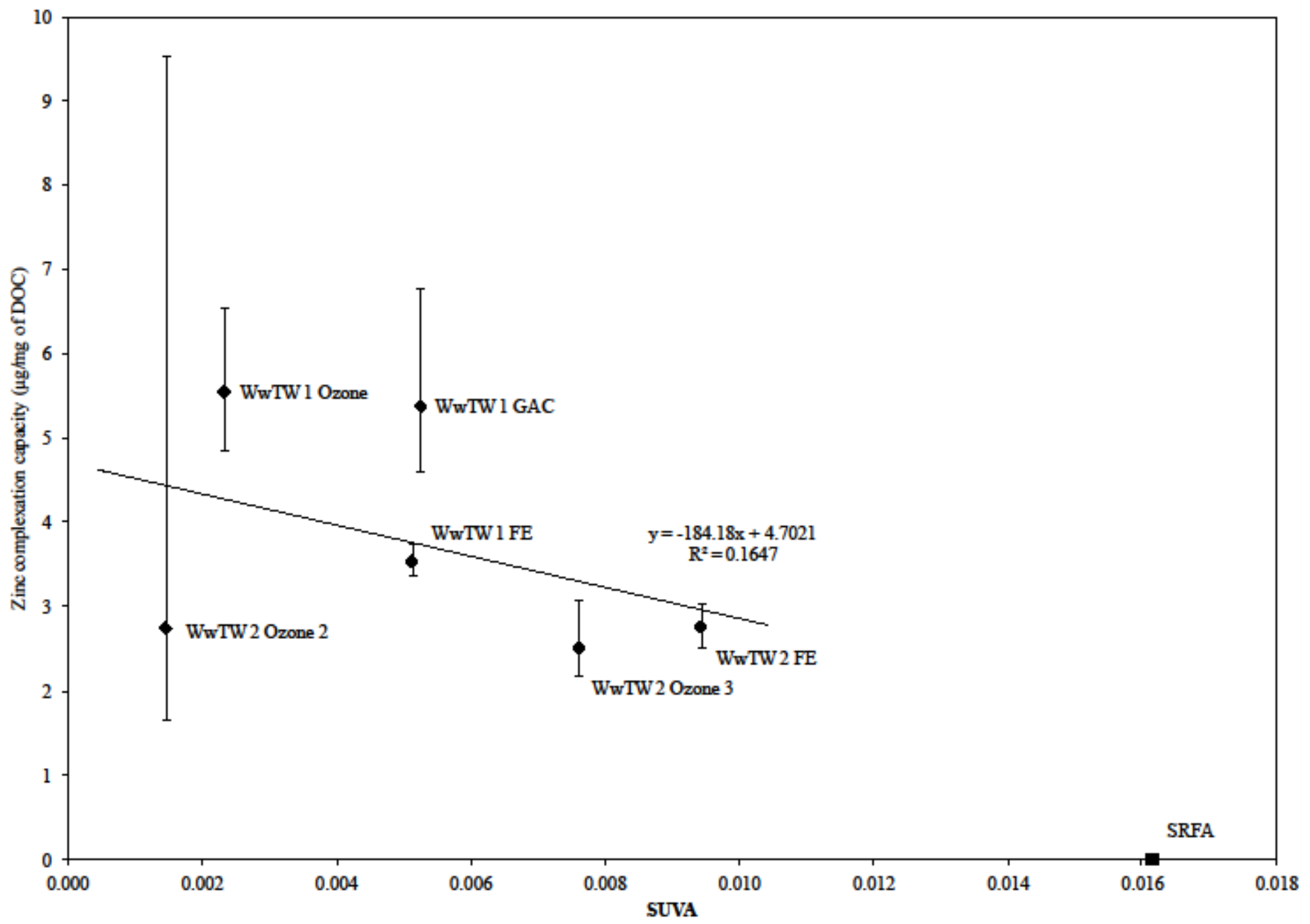

Figure 6 The relationship between zinc complexation capacity and SUVA. The error bars represent the complexation capacity $95 \%$ confidence interval range. The solid line represents the linear relationship between complexation capacity and SUVA for the effluent samples (excludes SRFA). 